\title{
Building a global materials community
}

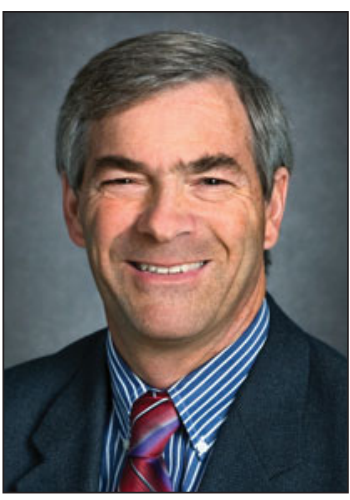

Jim De Yoreo 2011 MRS President
At the beginning of my term as president of the Materials Research Society, I used this column to celebrate the transformative activities and accomplishments that 2011 would bring to MRS. I highlighted the airing of the NOVA series Making Stuff, the launching of MRS Communicationsthe first new MRS journal in 25 years - and perhaps most importantly, the changes in governance at MRS that have helped us create a sustainable approach to strategic planning that transcends the presidential term. The blossoming of our communications portfolio and the partnership with Cambridge University Press are direct results of this new approach, and the new strategic initiative to create the future of MRS meetings that Duane Dimos and I discussed in last month's column would not be possible without it.

What these three products—Making Stuff, MRS Communications, and the MRS Meetings portfolio - have in common is that they serve to connect us, both to the public and to one another. Furthering this interconnectedness advances the core mission of MRS to ". . . build a dynamic, interactive, global community of materials scientists." Unfortunately, it is the interconnectedness of the global materials community and our ability to fulfill this core mission that concerns me the most as I leave this Office; and it is to the entire global community of materials scientists that I address this letter.

When the Materials Research Society was founded in 1973, it was born from a vision for materials science that was blind to the boundaries between both scientific disciplines and nations. As the materials endeavor expanded globally and the MRS concept gained visibility, new MRS-X's were created to better serve materials scientists in other regions and countries, eventually resulting in creation of the International Union of Materials Research Societies (IUMRS).

On balance, this expansion has been invigorating for our science and has allowed cultural differences and local needs to be accommodated and addressed. However, there is a negative side to this natural evolution that we must work to defeat. By the very nature of self-identification as groups, we draw boundaries around ourselves and we begin to measure our success by how many members we have or how big our bank accounts have become. The result is an atmosphere of competitiveness rather than partnership, which impedes the very mission of the MRS movement, our reason for being and the greatest value we can bring to our members. This natural tendency diverts IUMRS away from its communal role toward a divisive mission of codifying boundaries.

With this threat to our mission in mind, my parting message to you, my colleagues, is to resist this trend at all turns. Go out of your way to break down the walls that our organizations build around us. If you are a volunteer in your local, national, or regional Society, then challenge the notion that we exist as organizations simply to further those organizations. Work to build inter-society partnerships that bring materials researchers together rather than segregating them from one another. Become a member of more than one materials society. In short, work to build the dynamic, interactive global community that the MRS founders envisioned.

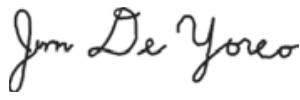

Jim De Yoreo

2011 MRS President 